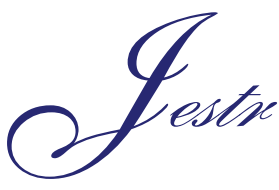

\title{
Application of Taguchi approach and Utility Concept in solving the Multi-objective Problem when turning AISI 202 Austenitic Stainless Steel
}

\author{
M. Kaladhar,", K. V. Subbaiah ${ }^{2}$, Ch. Srinivasa Rao² and K. Narayana Rao ${ }^{3}$ \\ ${ }^{1}$ Department of Mechanical Engineering, Anil Neerukonda Institute of Technology, Visakhapatnam, Andhra Pradesh, India \\ ${ }^{2}$ Department of Mechanical Engineering, Andhra University, Visakhapatnam, Andhra Pradesh, India. \\ ${ }^{3}$ Department of Mechanical Engineering, Government Polytechnic, Visakhapatnam, Andhra Pradesh, India.
}

Received 18 August 2010; Revised 19 October 2010; Accepted 25 January 2011

\begin{abstract}
The traditional Taguchi method is widely used for optimizing the process parameters of a single response problem. Optimization of a single response results the non-optimum values for remaining. But, the performance of the manufactured products is often evaluated by several quality characteristics/responses. Under such circumstances, multi-characteristics response optimization may be the solution to optimize multi-responses simultaneously. In the present work, a multi-characteristics response optimization model based on Taguchi and Utility concept is used to optimize process parameters, such as speed, feed, depth of cut, and nose radius on multiple performance characteristics, namely, surface roughness (Ra) and material removal rate (MRR) during turning of AISI 202 austenitic stainless steel using a CVD coated cemented carbide tool. Taguchi's L8 orthogonal array (OA) is selected for experimental planning. The experimental result analysis showed that the combination of higher levels of cutting speed, depth of cut, and nose radius and lower level of feed is essential to achieve simultaneous maximization of material removal rate and minimization of surface roughness. The ANOVA and F-tests are used to analyze the results. Further, the confirmation tests are conducted and the results are found to be within the confidence interval.
\end{abstract}

Keywords: Multi response Optimization, Taguchi method, Utility concept, austenitic stainless steel, CVD coated carbide tool, Surface roughness \& MRR.

\section{Introduction}

Surface roughness has become the most significant technical requirement and it is an index of product quality. In order to improve the tribological properties, fatigue strength, corrosion resistance and aesthetic appeal of the product, a reasonably good surface finish is desired. Nowadays, the manufacturing industries specially are focusing their attention on dimensional accuracy and surface finish. In order to obtain optimal cutting parameters to achieve the best possible surface finish, manufacturing industries have resorted to the use of handbook based information and operators' experience. This traditional practice leads to improper surface finish and decrease in the productivity due to sub-optimal use of machining capability. This causes high manufacturing cost and low product quality [1].

In addition to the surface finish quality, the material removal rate (MRR) is also an important characteristic in turning operation and high MRR is always desirable [22]. Hence, there is a need to optimize the process parameters in a systematic way to achieve the output characteristics/responses by using experimental methods and stastical models. Dr. Taguchi employed design

*E-mail address: kaladhar2k@gmail.com

ISSN: 1791-2377 (C) 2011 Kavala Institute of Technology. All rights reserved. of experiments (DOE),which is one of the most important and efficient tools of total quality management (TQM) for designing high quality systems at reduced cost. Taguchi emphasizes on the fact that Quality provides robustness and immune to the uncontrollable factors in the manufacturing state. This approach helps to reduce the large number of experimental trials when the number of process parameters increases. Most of the works have been published so far focused on single response performance characteristic optimization by using Taguchi approach [3], [8], [9], [10], [16], [17], [23]. But the Taguchi approach is designed for optimizing the single response problems. It is not fit for optimizing the multiresponse problems [20]. Optimization of a single response results the non-optimum values for remaining responses. In solving many problems in engineering, it is necessary to consider the application of multi-response optimization, because the performance of the manufactured products is often evaluated by several quality characteristics/responses. Though the Taguchi approach is used for a single response problem, most of the researchers proposed various methods for multi-response problem by modifying it [22]. Some of the researchers has been efficiently utilized the Taguchi method 
and utility concept for multi-response optimization for various processes such as face milling [12], gas tungsten arc welding [19], magnetic-field-assisted abrasive flow machining [18], V-process casting [5], electro-chemical honing [2], thermoforming process of polymeric foams [7], turning of Free-machining [22]. AISI 202 austenitic stainless steel finds its application in general industrial and process-industry machinery and equipment, electrical machinery/equipment, automotive industry, Structural, bus body etc., [11]. But, it is found that no work has been reported in the literature on multi-response optimization of surface roughness and material removal rate in turning of AISI 202 austenitic stainless steel. In the present investigation, a multi characteristics optimization model based on Taguchi method and utility concept has been employed to determine the best combination of the machining parameters such as cutting speed, feed, depth of cut and nose radius to attain the minimum surface roughness and maximum MRR simultaneously. The predictive models obtained for performance measures. Confirmation tests are also conducted to verify the results.

\section{Materials and Methods}

\subsection{Work piece material}

The work piece material used for present work was AISI 202 austenitic stainless steel. There are two types of austenitic stainless steel: 300-series and 200-series. Most stainless steel used around the world is of the 300 -series type. The 200 series stainless steels have become popular in the Asian continent, particularly as an alternative to 300 series in view of increase in nickel prices. The 200 series are non-magnetic and austenitic. Hence, it is very difficult to distinguish from widely used 300 series of stainless steel, which are also non-magnetic. One such family of stainless steels is the 200 -series. The 200 -series are a technically valid family of stainless steels but, like all stainless steel they have their limitations [4]. The chemical composition of AISI 202 is given in Table 1.

Table 1. Chemical composition (wt \%) of AISI 202.

\begin{tabular}{cccc}
\hline $\mathrm{Cr} \%$ & Ni \% & Mn\% & N\% \\
17.0 & 4.0 & 7.5 & 0.25 \\
\hline
\end{tabular}

\subsection{Cutting inserts and cutting conditions}

Coated carbide tools have shown better performance when compared to the uncoated carbide tools [14]. For this reason, commonly available Chemical Vapor Deposition (CVD) of Ti $(\mathrm{C}, \mathrm{N})$ $+\mathrm{Al}_{2} \mathrm{O}_{3}$ coated cemented carbide inserts of 0.8 and $0.4 \mathrm{~mm}$ as nose radius are used in the present experimental investigation. The Process parameters and levels used in the experiment, experimental set up and conditions are given in the Tables 2 and 3.

Table 2. Experimental set up and conditions.

\begin{tabular}{ll}
\hline Machine tool: & $\begin{array}{l}\text { ACE Designer LT-16XL CNC lathe, } 7.5 \mathrm{~kW} \\
(10 \mathrm{hp}) \text { and } 4000 \mathrm{rpm}, \text { India }\end{array}$ \\
$\begin{array}{l}\text { Work specimen } \\
\begin{array}{l}\text { Material: }\end{array}\end{array}$ & AISI 202 austenitic stainless steel
\end{tabular}

\begin{tabular}{ll} 
Size: & Ф25 mm x 70mm \\
Cutting t inserts: & CNMG 120408, CNMG 120404 (SECO make) \\
Tool material: & CVD coated cemented carbide (TP-2500) \\
Tool holder: & PCLNL 252570012 (ISO specification) \\
Tool holder: & Dry machining \\
\hline
\end{tabular}

Table 3. Process parameters and levels used in the experiment.

\begin{tabular}{cccc}
\hline Code & Process parameters & Level 1 & Level 2 \\
\hline A & Cutting speed $(\mathrm{m} / \mathrm{min})$ & 111 & 200 \\
B & Depth of cut $(\mathrm{mm})$ & 0.25 & 0.75 \\
C & Feed (mm/rev.) & 0.15 & 0.25 \\
D & Nose radius $(\mathrm{mm})$ & 0.4 & 0.8 \\
\hline
\end{tabular}

\subsection{Experimental procedure}

Turning is a popularly used machining process. The CNC machines play a major role in modern machining industry to enhance product quality as well as productivity [21]. In the present work, two levels, four factors and eight experiments are identified. Appropriate selection of orthogonal array is the first step of Taguchi approach. The minimum number of experimental trails required in orthogonal array is given by $\mathrm{N}_{\min }=(\mathrm{L}-1) \mathrm{F}+1$; Where $\mathrm{F}=$ no. of factors $=4, \mathrm{~L}=$ no. of levels $=2, \mathrm{~N}_{\min }=5$; According to Taguchi approach L8 has been selected. Cutting tests were carried out on 10 hp CNC lathe machine under dry conditions. The machining process on $\mathrm{CNC}$ lathe is programmed by speed, feed, and depth of cut. In total 8 work pieces are prepared. These work pieces are cleaned prior to the experiments by removing $0.5 \mathrm{~mm}$ thickness of the top surface from each work piece in order to eliminate any surface defects and wobbling. Two different nose radii of CVD coated inserts have been taken to study the effect of tool geometry. The rough nesses of machined surfaces are measured by a Mitutoyo SJ-201 surface roughness tester and measurements are repeated 3 times. The experimental design and results are given in Table 4.

Table 4. L8 orthogonal array with the responses.

\begin{tabular}{cccccc}
\hline \multicolumn{4}{c}{ Levels } & \multicolumn{2}{c}{ Responses } \\
\hline $\mathrm{A}$ & $\mathrm{B}$ & $\mathrm{C}$ & $\mathrm{D}$ & $\mathrm{Ra}$ & $\mathrm{MRR}\left(\mathrm{cm}^{3} / \mathrm{min}\right)$ \\
\hline 1 & 1 & 1 & 1 & 1.32 & 4.162 \\
1 & 1 & 2 & 2 & 1.56 & 6.937 \\
1 & 2 & 1 & 2 & 0.813 & 12.487 \\
1 & 2 & 2 & 1 & 2.736 & 20.812 \\
2 & 1 & 1 & 2 & 0.7 & 7.5 \\
2 & 1 & 2 & 1 & 1.713 & 12.5 \\
2 & 2 & 1 & 1 & 1.3 & 22.5 \\
2 & 2 & 2 & 2 & 1.683 & 37.5 \\
\hline
\end{tabular}

\section{Methodology:}

\section{Taguchi Approach}

The reason why Design of experiment (DOE) is selected rather 
than the other approaches to conduct experiment is that it has a systematic planning of experiments. Taguchi technique for DOE has been the most widely used technique for the last two decades. One of the important steps involved in Taguchi's technique is selection of orthogonal array (OA). Which will further help to conduct experiments to determine the optimum level for each process parameters and establish the relative importance of individual process parameters. An OA is a small set from all possibilities which helps to determine least no.of experiments. To obtain optimum process parameters setting, Taguchi proposed a statistical measure of performance called signal to noise ratio [15]. This ratio considers both the mean and the variability. In addition to $\mathrm{S} / \mathrm{N}$ ratio, ANOVA is used to indicate the influence of process parameters on performance measures.

\section{Utility Concept}

Quality is a key attribute that customers use to evaluate product or services. So the modern quality control and improvement programs have to make their products more acceptable by the customers. On the other hand, customer evaluates a product performance based on a number of diverse qualitative characteristics. To improve the rational decision making, the evaluations of various attributes should be combined to give a composite index. Such a composite index is known as utility of a product. The sum of utilities of each quality attribute represents the overall utility of a product. It is difficult to obtain the best combination of process parameters, when there are multi-responses to be optimized. The adoption of weights in the utility concept help in this difficult situations by differentiating the relative importance of various responses [5]. If $x_{i}$ represents the measure of effectiveness of $i$ th process response characteristic and $n$ represents no. of responses, then the overall utility function can be written as [6]:

$U\left(x_{1}, x_{2} \ldots x_{n}\right)=f\left[U_{1}\left(x_{1}\right), U_{2}\left(x_{2}\right), \ldots \ldots U_{n}\left(x_{n}\right)\right]$

where $U\left(x_{1}, x_{2} \ldots x_{n}\right)$ is the overall utility of $\mathrm{n}$ process response characteristics and $U_{i}\left(x_{i}\right)$ is utility of $i$ th response characteristic. Assignment of weights is based on the requirements and priorities among the various responses. Therefore the general form or weighted from of Eq.(1) can be expressed as

$$
U\left(x_{1}, x_{2} \ldots x_{n}\right)=\sum_{i=1}^{n} W_{i} U_{i}\left(x_{i}\right)
$$

Where $\sum_{i=1}^{n} W_{i}=1$, Where $W_{i}$ is the weight assigned to the $i$ th response characteristic.

\section{Results and Analysis}

The objective of the present work is to minimize surface roughness and maximize the MRR in turning process optimization. The following equation is used to calculate MRR,

$\mathrm{MRR}=f v d\left(\mathrm{~cm}^{3} / \mathrm{min}\right)$

Where $f$ is feed rate in $\mathrm{mm} / \mathrm{rev}, v$ is cutting speed in $\mathrm{m} / \mathrm{min}$, $d$ is depth of cut in mm. Taguchi technique uses $\mathrm{S} / \mathrm{N}$ ratio as a performance measure to choose control levels. The $\mathrm{S} / \mathrm{N}$ ratio considers both the mean and the variability. In the present work, a multi-response methodology based on Taguchi technique and Utility concept is used for optimizing the multi-responses ( $R a$ and MRR). Taguchi proposed many different possible $\mathrm{S} / \mathrm{N}$ ratios to obtain the optimum parameters setting [15]. Two of them are selected for the present work. Those are, Smaller the better type $\mathrm{S} / \mathrm{N}$ ratio for $\mathrm{Ra}$,

$$
\begin{array}{r}
{\left[\eta_{1}\right]=-10 \log _{10}\left[R_{a}^{2}\right] ;} \\
\text { Larger the better S/N } \\
{\left[\eta_{2}\right]=-10 \log _{10}\left[\frac{1}{M R R^{2}}\right]}
\end{array}
$$$$
\text { Larger the better } \mathrm{S} / \mathrm{N} \text { ratio for MRR }
$$

From the utility concept, the multi-response $\mathrm{S} / \mathrm{N}$ ratio of the overall utility value is given by

$$
\eta_{o b s}=W_{1} \eta_{1}+W_{2} \eta_{2}
$$

Where $W_{1} \& W_{2}$ are the weights assigned to the Ra and MRR. Assignment of weights to the performance characteristics are based on experience of engineers, customer's requirements and their priorities. In the present work equal importance is given for both Ra and MRR. Therefore $W_{1} \& W_{2}=0.5$.

\section{Determination of optimal range for Surface roughness and MRR at single response stage:}

Performance of $\mathrm{Ra}$ at the optimum conditions (based on estimated average)

$$
\begin{aligned}
\bar{\mu}_{C_{1} D_{2}} & =\bar{C}_{1}+\bar{D}_{2}-\bar{T} \\
& =1.033+1.189-1.478 \\
& =0.7
\end{aligned}
$$

(From Table 4, $\bar{T}=1.478$ )

$C I==\sqrt{\frac{F_{95 \%, 1, d f_{\text {error }}}{ }^{*} V_{\text {error }}}{n_{\text {efficiency }}}}$ level,

Where $\eta_{\text {efficiency }}=\mathrm{N} / 1+$ dof of all parameters associated to that

$$
n_{\text {efficiency }}=\frac{8}{1+1+1}=2.666
$$

$V_{\text {error }}=0.072$ (from Table 7), $F_{95 \%, 1,3}=10.1$

$$
\begin{aligned}
C I & =\sqrt{10.1 * 0.0720 / 2.66}=\sqrt{0.27338} \\
& =\mathbf{0 . 5 2 3}
\end{aligned}
$$

The predicted optimal range at $95 \%$ confidence level is obtained as,

$$
\begin{aligned}
0.744-0.523 & \leq \bar{\mu}_{C_{1} D_{2}} \leq 0.744+0.523 \\
0.221 & \leq \bar{\mu}_{C_{1} D_{2}} \leq 1.267
\end{aligned}
$$


Performance of MRR at the optimum conditions (based on estimated average)

$$
\begin{aligned}
\bar{\mu}_{B_{2} A_{2}} & =\bar{B}_{2}+\bar{A}_{2}-\bar{T} \\
& =23.325+20.00-15.55 \\
& =27.775
\end{aligned}
$$

(From Table 4, $\bar{T}=15.55)$

$n_{\text {efficiency }}=\frac{8}{1+1+1}=2.666$

$V_{\text {error }}=26.577$ (from Table 8$), F_{95 \%, 1,3}=10.1$

$$
\begin{aligned}
C I & =\sqrt{10.1 * 26.577 / 2.66}=\sqrt{100.9126} \\
& =\mathbf{1 0 . 0 4 5}
\end{aligned}
$$
tained as,

The predicted optimal range at $95 \%$ confidence level is ob-

$$
\begin{aligned}
27.775-10.045 & \leq \bar{\mu}_{B_{2} A_{2}} \leq 27.775+10.045 \\
17.73 & \leq \bar{\mu}_{B_{2} A_{2}} \leq 37.82
\end{aligned}
$$

\section{Analysis of Single response stage}

The optimal settings and the predicted optimal values for surface roughness and MRR are determined individually by Taguchi's approach. Table 6 shows these individual optimal values and its corresponding settings of the process parameters for the specified performance characteristics. Further, the ANOVA is used to determine the optimum combination of process parameters more accurately by investigating the relative importance of process parameters [12].Tables $7 \& 8$ reveal the results of ANOVA for Ra and MRR respectively. It is observed that the feed $(61.428 \%)$ is most significantly influences the $\mathrm{Ra}$ followed by nose radius $(25.96 \%)$. In case of MRR, depth of cut (63.183\%) is the most significant parameter followed by cutting speed $(20.697 \%)$. In both the cases, error contribution $(0.0838 \%)$ and $(0.104 \%)$ reveals that the interaction effect of the process parameters is negligible.

Table 5. Means of Surface roughness and MRR at different levels.

\begin{tabular}{cccccccccc}
\hline & \multicolumn{3}{c}{$\begin{array}{c}\text { Mean values of Ra } \\
(\boldsymbol{\mu m})\end{array}$} & \multicolumn{5}{c}{$\begin{array}{c}\text { Mean values of MRR } \\
\left(\mathbf{c m}^{3} / \mathbf{m i n}\right)\end{array}$} \\
\hline $\begin{array}{c}\text { Level/process } \\
\text { parameters }\end{array}$
\end{tabular}

Table 6. Individual optimal values and its corresponding settings of the process parameters.

\begin{tabular}{ccc}
\hline $\begin{array}{c}\text { Performance } \\
\text { Characteristics }\end{array}$ & $\begin{array}{c}\text { Optimum } \\
\text { parameter level }\end{array}$ & $\begin{array}{c}\text { Predicted } \\
\text { optimal level }\end{array}$ \\
\hline $\begin{array}{c}\text { Surface roughness } \\
\text { Material removal rate }\end{array}$ & $\begin{array}{c}\text { A2-B1-C1-D2 } \\
\text { A2-B2-C2-D2 }\end{array}$ & $\begin{array}{c}0.46 \mu \mathrm{m} \\
31.05 \mathrm{~cm}^{3} / \mathrm{min}\end{array}$ \\
\hline
\end{tabular}

Table 7. ANOVA results for Surface roughness (Ra).

\begin{tabular}{cccccc}
\hline Source & SS & DOF & MS & F & C (\%) \\
\hline A & 0.133 & 1 & 0.133 & 1.847 & 5.161 \\
B & 0.192 & 1 & 0.192 & 2.666 & 7.450 \\
C & 1.583 & 1 & 1.583 & 21.986 & 61.428 \\
D & 0.669 & 1 & 0.669 & 9.291 & 25.960 \\
Error & 0.216 & 3 & 0.072 & & 0.0838 \\
Total & 2.577 & 7 & & & \\
\hline
\end{tabular}

Table 8. ANOVA results for material removal rate (MRR).

\begin{tabular}{cccccc}
\hline Source & SS & DOF & MS & F & C (\%) \\
\hline A & 158.420 & 1 & 158.420 & 5.960 & 20.697 \\
B & 483.605 & 1 & 483.605 & 18.196 & 63.183 \\
C & 120.901 & 1 & 120.901 & 4.549 & 15.795 \\
D & 2.475 & 1 & 2.475 & 0.093 & 0.323 \\
Error & 79.732 & 3 & 26.577 & & 0.104 \\
Total & 765.401 & 7 & & & \\
\hline
\end{tabular}

\section{Analysis of Multi- response stage}

The optimal combination of process parameters (A2-B2-C1-D2) for simultaneous optimization of Surface roughness (Ra) and material removal rate (MRR) is obtained by the mean values of the multi-response $\mathrm{S} / \mathrm{N}$ ratio of the overall utility value are shown in Table 10. According to the Table 11 for the results of ANOVA multiple performance characteristics, depth of cut $(54.439 \%)$ is

\begin{tabular}{|c|c|c|c|c|c|c|}
\hline \multicolumn{4}{|c|}{ Levels } & \multicolumn{3}{|c|}{$\mathrm{S} / \mathrm{N}$ ratio(dB) } \\
\hline$A$ & B & $\mathrm{C}$ & D & $\eta_{1}$ for $R a$ & $\eta_{2}$ for MRR & $\boldsymbol{\eta}_{o b s}$ \\
\hline 1 & 1 & 1 & 1 & -2.41148 & 12.38708 & 4.987803 \\
\hline 1 & 1 & 2 & 2 & -3.86249 & 16.82406 & 6.480784 \\
\hline 1 & 2 & 1 & 2 & 1.798189 & 21.92951 & 11.86385 \\
\hline 1 & 2 & 2 & 1 & -8.74232 & 26.36649 & 8.812082 \\
\hline 2 & 1 & 1 & 2 & 3.098039 & 17.50123 & 10.29963 \\
\hline 2 & 1 & 2 & 1 & -4.67515 & 21.9382 & 8.631527 \\
\hline 2 & 2 & 1 & 1 & -2.27887 & 27.04365 & 12.38239 \\
\hline 2 & 2 & 2 & 2 & -4.52168 & 31.48063 & 13.47947 \\
\hline
\end{tabular}
the most significant parameter affecting the performance followed by the cutting speed $(33.442 \%)$. The percent contribution of the nose radius $(11.169 \%)$ is lower and the feed is much lower, being $0.948 \%$. The error contribution $(1.973 \%)$ reveals that the interaction effect of the process parameters is negligible.

Table 9. L8 OA with multi-response $\mathrm{S} / \mathrm{N}$ ratios.

Table 10. Means of $\eta_{\text {obs }}$ at different levels.

\begin{tabular}{ccccc}
\hline & \multicolumn{5}{c}{ Mean values of $\boldsymbol{\eta}_{\text {obs }}$} \\
\hline Level / Process parameters $\rightarrow$ & A & B & C & D \\
\hline 1 & 8.036 & 7.6 & 9.883 & 8.703 \\
2 & 11.198 & 11.634 & 9.351 & 10.531 \\
\hline
\end{tabular}


Table 11. ANOVA results for multi-response case.

\begin{tabular}{cccccc}
\hline Source & SS & DOF & MS & F & C (\%) \\
\hline A & 19.998 & 1 & 19.998 & 50.842 & 33.442 \\
B & 32.554 & 1 & 32.554 & 82.752 & 54.439 \\
C & 0.5670 & 1 & 0.5670 & 1.441 & 0.948 \\
D & 6.679 & 1 & 6.679 & 16.978 & 11.169 \\
Error & 1.18 & 3 & 0.3933 & & 1.973 \\
Total & 59.798 & 7 & & & \\
\hline
\end{tabular}

\section{Interpretation of plots}

The data is given in Tables 4-7 and plots are developed with the help of a software package MINITAB 14. These results are analyzed using ANOVA for the purpose of identifying the significant factors, which affect the surface roughness and material removal rate. The above plots show the variation of individual response with the four parameters i.e. cutting speed, feed, depth of cut and nose radius separately. In the plots, the $\mathrm{x}$-axis indicates the value of each process parameter at two level and $y$-axis the response value. Horizontal line indicates the mean value of the response. Figure 1 shows the main effect plot for surface roughness. The results show that with the increase in cutting speed and the nose radius there is an increment in Ra value. The feed and the depth of cut are directly proportional to the corresponding Ra values. Figure 2 shows the main effect plot for MRR. It is observed that the maximum MRR is obtained at the $200 \mathrm{~m} / \mathrm{min}$ of cutting speed, $0.25 \mathrm{~mm} / \mathrm{rev}$ of feed and $0.75 \mathrm{~mm}$ depth of cut. The flat line almost shows that there is a little effect due to nose radius. Figure 3 shows the optimum levels of process parameters for the multi-response optimization are thus determined to be A2-B2-C1-D2. Figure 4 illustrates the interaction effects of process parameters for the multi-response optimization. It is observed that the lines are parallel to each other in the plots. If the lines are parallel and not overlapping then there is little or no evidence of an interaction in the parameters. There is less interaction effect between the feed and nose radius.

Table 12. Comparison of Results.

\begin{tabular}{cccccc}
\hline & $\begin{array}{c}\text { Perfor- } \\
\text { mance } \\
\text { charac- } \\
\text { teristics }\end{array}$ & $\begin{array}{c}\text { Op- } \\
\text { timal } \\
\text { setting } \\
\text { level }\end{array}$ & $\begin{array}{c}\text { Predicted } \\
\text { optimal } \\
\text { values }\end{array}$ & $\begin{array}{c}\mathbf{9 5 \%} \\
\text { Confidence } \\
\text { interval } \\
\text { (CICE) }\end{array}$ & $\begin{array}{c}\text { Actual con- } \\
\text { firmation } \\
\text { experiment } \\
\text { values }\end{array}$ \\
\hline $\begin{array}{c}\text { Single- } \\
\text { response } \\
\text { optimiza- } \\
\text { tion }\end{array}$ & Ra & $\begin{array}{c}\text { A2-B1- } \\
\text { C1-D2 }\end{array}$ & $0.46 \mu \mathrm{m}$ & $0.221 \leq \bar{\mu}_{C_{1} D_{2}} \leq 1.267$ & $0.693 \mu \mathrm{m}$ \\
$\begin{array}{c}\text { Multi- } \\
\text { response } \\
\text { optimiza- } \\
\text { tion }\end{array}$ & MRR & $\begin{array}{c}\text { A2-B2- } \\
\text { C2-D2 }\end{array}$ & $\begin{array}{c}31.05 \mathrm{~cm}^{3} / \\
\mathrm{min}\end{array}$ & $17.73 \leq \bar{\mu}_{B_{2} A_{2}} \leq 37.82$ & $\begin{array}{c}37.5 \\
\mathrm{~cm}^{3} / \mathrm{min}\end{array}$ \\
\hline
\end{tabular}

\section{Optimality Confirmation:}

Once the optimal level is selected, the next step is to predict and verify the improvement of the value of multiple responses of AISI202.The predicted optimal value $\left(\eta_{\text {opt }}\right)$ can be calculated by means of additive law.

$\eta_{o p t}=m+\sum_{j=1}^{n}\left[\left(m_{i, j}\right)_{\max }-m\right]$

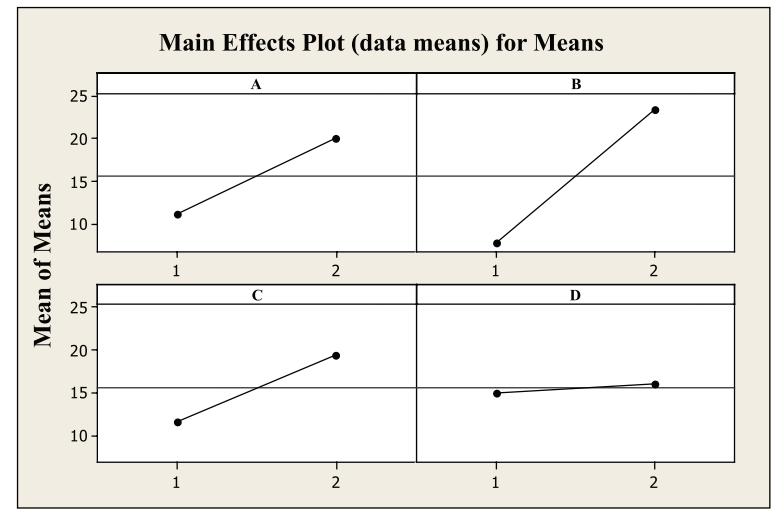

Figure 1. Main effect plot for Ra

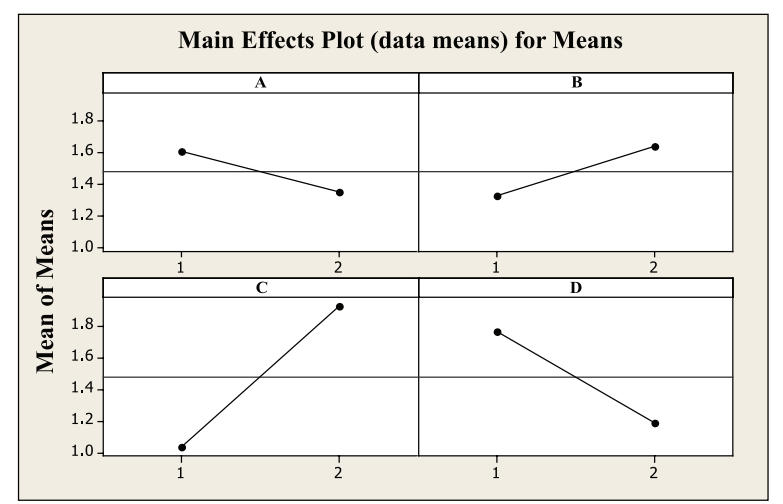

Figure 2. Main effect plot for MRR

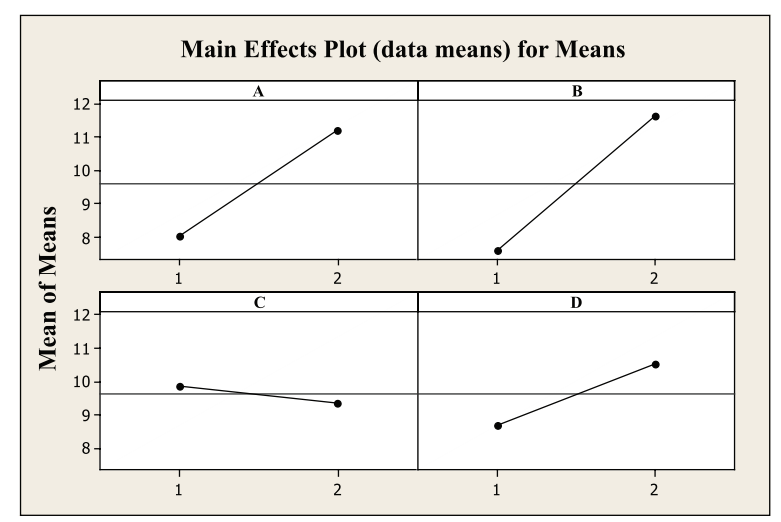

Figure 3. Main effects plot for Multi-response $\mathrm{S} / \mathrm{N}$ ratio

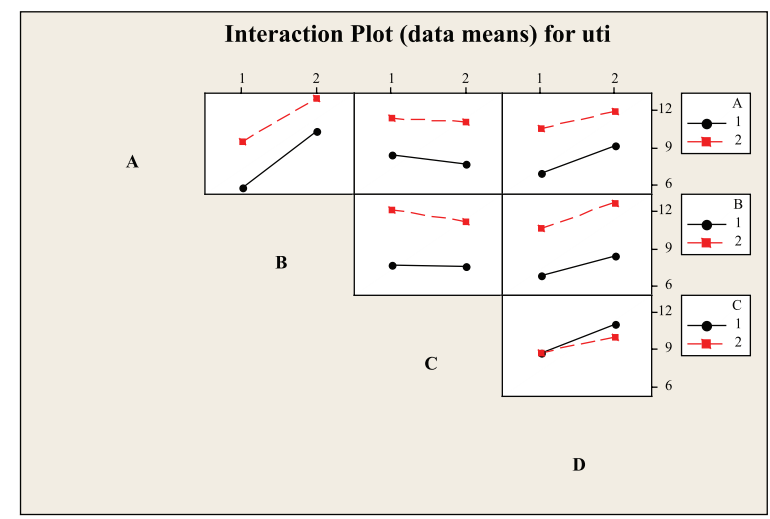

Figure 4. Interaction plot for Multi-response 
Where $m=$ overall mean of $\eta$ with eight trials; $\left(m_{i j}\right)_{\max }=\mathrm{S} / \mathrm{N}$ ratio at optimal level and parameter; $n$ is the number of main designing parameters that affect the machining process. The predicted optimal $\mathrm{S} / \mathrm{N}$ ratio of multiple responses $\left(\eta_{\text {opt }}\right)$ for the optimum parameter levels (A2-B2-C1-D2) is $14.395 \mathrm{~dB}$. In order to validate, the experiment (two trials) is conducted according to the optimal parameters levels (A2-B2-C1-D2) and the corresponding values of performance measures are taken. The average value of surface roughness is $1.159 \mu \mathrm{m}$ and the calculated value of MRR is $22.5 \mathrm{~cm}^{3} / \mathrm{min}$. The multi-response $\mathrm{S} / \mathrm{N}$ ratio of overall utility value $\left(\eta_{\text {obs }}\right.$ ) obtained by using Eq.[1] is $12.880 \mathrm{~dB}$. The confidence interval (at $95 \%$ ) value of $\eta_{\text {opt }}$ for the predicted mean on a confirmation experiment run can be computed using the following equation.

$$
\begin{aligned}
C I & =\sqrt{F_{95 \%, 1, d o f_{\text {error }}} * V_{\text {error }}\left(\frac{1}{n_{\text {efficiency }}}+\frac{1}{R}\right)} \\
& = \pm \mathbf{2 . 0 4 7 6}
\end{aligned}
$$

$F_{95 \%, 1, \text { dof error }}=$ F value at $95 \%$ confidence level $=10.1$;

$V_{\text {error }}=0.3933($ from Table 11)

$n_{\text {efficiency }}=\frac{N}{1+d}=\frac{9}{1+4}=1.8$

$\mathrm{d}=$ Total degree of freedom in associated with process parameters $\mathrm{R}=$ Trial number for confirmation test $=2$.

$$
\begin{aligned}
\bar{\mu}_{B_{2} A_{2}} & =\bar{B}_{2}+\bar{A}_{2}-\bar{T} \\
& =11.634+11.198-9.6171 \\
& =13.215
\end{aligned}
$$

(From Table 9, $\bar{T}=9.6171$ )

The predicted optimal range for optimal multi-respsponse $\mathrm{S} / \mathrm{N}$ ratio at $95 \%$ confidence level is obtained as,

$13.215-2.0476<\mu_{B_{2} A_{2}}<13.215+2.0476$

$$
11.167<\bar{\mu}_{B_{2} A_{2}}<15.262
$$

The prediction error $=\eta_{\text {opt }}-\eta_{\text {obs. }}$

$$
\begin{aligned}
& =14.395-12.88 \\
& =1.515 \mathrm{~dB}
\end{aligned}
$$

From the above relation, the prediction error is within the respective CI (at $95 \%$ ) value of $\pm 2.0476 \mathrm{~dB}$. Hence, it is observed that from the results of confirmation test, the adequacy of the additivity law model is justified and the results are validated.

\section{Conclusions}

The present work is concerned with exploring to determine the optimum setting of process parameters for multi-response optimization during turning of AISI 202 austenitic stainless steel using CVD coated carbide insert. On the basis of Taguchi approach and Utility concept, a model was developed to achieve this. The L8 OA was used for experimental planning. In first stage (singleresponse), optimal settings and optimal values of Ra and MRR were obtained individually. And from their corresponding ANOVA results, the feed $(61.428 \%)$ is the most significant parameter followed by cutting speed $(20.697 \%)$ for $\mathrm{Ra}$, the depth of cut $(63.183 \%)$ is the most significant parameter followed by cutting speed $(20.697 \%)$ for MRR response. In second stage (multi-response), the analysis of means establishes that a combination of higher levels of cutting speed, depth of cut, nose radius and lower level of feed is necessary for obtaining the optimal value of multiple performances. Based on the ANOVA and F-test analysis, the most statistical significant and percent contribution of the process parameters for multiple performances are depth of cut, cutting speed, whereas feed and nose radius are less effective. In both the stages the interaction effect of process parameters is negligible. Table12 shows the results comparison. The validation experiment confirmed that the adequacy of law of additivity is justified. It is found that the proposed model based on Taguchi approach and Utility concept is simple, useful and provides an appropriate solution for multi-response optimization problems.

\section{References}

1. Akasawa. T. Effect of free-cutting additives on the machinability of austenitic stainless steels. J. Mater. Process. Technol. 43/144, 66 (2003).

2. A. K. Dubey. Multi-response optimization of electro-chemical honing using utility-based Taguchi approach. Int J Adv Manuf Technol 41, 749 (2009).

3. Anirban Bhattacharya, Santanu Das, P. Majumdar, Ajay Batish. Estimation of the effect of cutting parameters on surface finish and power consumption during high speed machining of AISI 1045 steel using Taguchi design and ANOVA. Prod. Eng. Res. Devel.3, 31 (2009).

4. Australian Stainless Steel Development Association (ASSDA). Technical bulletin 200 series stainless steel CRMN grades.1 (10), 2 (2006)

5. Barua PB, Kumar P, Gaindhar JL.Optimal setting of process parameters for multi-characteristic products using Taguchi design and utility-conceptan approach. Proc ICAMIE, University of Roorkee (India), pp. 839-842 (1997).

6. Bunn D. W. Analysis for optimal decisions. John Wiley \& Sons, New
York, (1982).

7. C. Yang \& S.-W. Hung, Optimising the thermoforming process of polymeric foams: an approach by using the Taguchi method and the utility concept Int J Adv Manuf Technol 24, pp. 353-360 (2004).

8. D. G. Thakur, B. Ramamoorthy, and L. Vijayaraghavan. Optimization of Minimum Quantity Lubrication Parameters in High Speed Turning of Superalloy Inconel 718 for Sustainable Developments., World Academy of Science, Engineering and Technology, pp. 54 (2009).

9. Hari Singh. Optimizing Tool life of Carbide Inserts for Turned parts using Taguchi's Design of Experiment Approach. Proceedings of International Multi Conference of Engineerings and Computer Scientists, Hong Kong, (2008).

10. H. Singh and P. Kumar. Quality Optimization of Turned Parts (En 24 Steel) by Taguchi Method. Productivity journal, 44 (1), 43 (2003).

11. International Stainless Steel Forum (ISSF). A Technical guide to chromemanganese austenitic stainless steel and advice for potential guide, pp.8- 
$10,(2005)$

12. Lin T. R. Optimisation technique for face milling stainless steel with multiple performance characteristics. Int J Adv Manuf Technol 19, 330 (2002).

13. M. Y. Wang and T. S. Lan: Parametric optimization on multi objective precision turning using Grey relational analysis.International Technology journal, 7, 1072 (2008).

14. Noordin M. Y., Venkatesh V. C., Sharif. S., Elting. S., Abdullah. A. Application of response surface methodology in describing the performance of coated carbide tools when turning AISI 1045 steel. Journal of Materials Processing Technology 145, 46 (2004).

15. P. J. Ross.Taguchi Techniques for Quality Engineering, McGraw-Hill Book Company, NewYork, (1996).

16. S. S. Mahapatra et al. Parametric analysis and Optimization of cutting parameters for turning operations based on Taguchi method. Proceedings of the International Conference on Global Manufacturing and Innovation, Coimbatore, India, (2006).

17. S. Thamizhmanii, S. Saparudin, S. Hasan, Analyses of surface roughness by turning process using Taguchi method, Journal of Achievements in Materials and Manufacturing, 20 (2), 503 (2007).
18. Singh S, Shan H. S., Kumar P. Parametric optimization of magnetic-field assisted abrasive flow machining by the Taguchi method. Qual Rel Eng Int, 18:27, (2002).

19. Tarng Y. S., Yang W. H. Optimization of the weld bead geometry in gas tungsten arc welding by the Taguchi method. Int J Adv Manuf Technol 14, 549 (1998).

20. Tatjana V. Sibalija, Vidosav D. Mestrovic Novel Approach to MultiResponse Optimization for Correlated Responses. J. of the Braz. Soc. of Mech. Sci. \& Eng. 38, 1, (2010).

21. Tian-Syung Lan. Taguchi optimization of Multi objective CNC machining using TOPSIS. International Technology journal. 8 (6), 917 (2009).

22. V. N. Gaitonde, Karnik, Paulo Davim, Multiperformance Optimization in turning of Free-machining Steel Using Taguchi Method and Utility concept. Journal of Materials Engineering and Performance,18 (3), 231 (2009).

23. Young-Kug Hwang et al, Evalution of Machinibility According to the Changes in Machine tools and cooling lubrication environments and Optimization of Cutting conditions using Taguchi Method. International journal of Processing Engineering and manufacturing. 10 (3), 65 (2009). 